\title{
Épître dédicatoire à l'édition des comédies de Térence par Willich (1550)
}

\section{Gregor Wagner de Reszel}

Christiane Deloince-Louette et Jean-Yves Vialleton (éd.)

\section{(2) OpenEdition Journals}

Édition électronique

URL : http://journals.openedition.org/rhetorique/574

DOI : 10.4000/rhetorique. 574

ISSN : 2270-6909

Éditeur

UGA Éditions/Université Grenoble Alpes

Édition imprimée

ISBN : 978-2-37747-029-7

Référence électronique

Gregor Wagner de Reszel, «Épître dédicatoire à l'édition des comédies de Térence par Willich (1550) », Exercices de rhétorique [En ligne], 10 | 2017, mis en ligne le 26 décembre 2017, consulté le 02 octobre 2020. URL : http://journals.openedition.org/rhetorique/574 ; DOI : https://doi.org/10.4000/rhetorique 574

Ce document a été généré automatiquement le 2 octobre 2020.

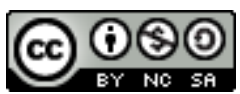

Les contenus de la revue Exercices de rhétorique sont mis à disposition selon les termes de la Licence Creative Commons Attribution - Pas d'Utilisation Commerciale - Partage dans les Mêmes Conditions 4.0 International. 


\title{
Épître dédicatoire à l'édition des comédies de Térence par Willich (1550)
}

\author{
Gregor Wagner de Reszel
}

Christiane Deloince-Louette et Jean-Yves Vialleton (éd.)

Une invitation à la lecture de Térence : l'épître dédicatoire de Gregor Wagner à l'édition des Comédies par Josse Willich

Gregor Wagner de Reszel (Gregorius Wagnerus Resellianus), né en 1512 et mort en 1559, fut cordonnier, maître d'école, auteur dramatique et théologien, selon la Deutsche Biographie ${ }^{1}$. Il est surtout connu comme le demi-frère du médecin et humaniste prussien Josse Willich (Jodocus Willichius, 1501-1552) qui veilla sur ses études à l'Université de Francfort-sur-l'Oder où il enseignait depuis 1530. Pour l'édition commentée des comédies de Térence que publie Josse Willich en 1550 chez l'imprimeur Johann Eichorn ${ }^{2}$, il rédige une longue épître dédicatoire qu'il adresse à son neveu. Cette épître, qui fait l'éloge de Térence et de son œuvre, sera systématiquement rééditée dans toutes les éditions de Térence qui proposent les commentaires de Willich ${ }^{3}$.

Nous utilisons ici le texte, relu et corrigé, de l'édition de Cologne : Commentaria in omnes Terentii fabulas compendiosa, quibus per singulas scenas ratio inuentionis, dispositionis et eloquutionis, cum quorundam locorum obscuriorum explanatione ostensa, studiosis auditoribus primarum artium proponitur. Auto[re] D[octore] Iodoco Vuillichio Reselliano. Adiectum est exemplar Terentii caeteris multo castigatius. Coloniae, Apud Haered. Arnol. Birkmanni. Anno 1555. Pour plus de clarté, nous avons développé les abréviations, à l'exception de celles des titres des comédies de Térence, que nous avons cependant harmonisées. Nous conservons les mots en grec dans le texte original et nous les accompagnons dans la traduction d'une translittération entre parenthèses. De même, nous traduisons les mots techniques latins en 
rappelant entre parenthèses les termes originaux. Le paragraphage est le nôtre. Le texte latin se présente en continu, avec seulement les alinéas des deux séquences de vers.

L'épître de Gregor Wagner est construite en deux grandes parties, la première consacrée à l'éloge de l'art de Térence, la deuxième à l'utilité de Térence pour l'éducation des jeunes gens. La première partie se subdivise elle-même en deux temps, distinguant rhétorique et éthique. Elle traite d'abord de la dispositio et de la proprietas chez Térence, avec un long éloge de l'ordre qu'exigent tant l'art oratoire que l'art dramatique, et plusieurs exemples empruntés à L'Andrienne et à l' Heautontimoroumenos. Elle illustre ensuite le lieu commun cicéronien de la comédie comme miroir de la vie, en mettant en valeur chez Térence la notion de decorum et le traitement des émotions (affectus). La deuxième partie s'ouvre sur un éloge de Willich et de son travail, affirme ensuite la nécessité d'éduquer les jeunes gens par l'étude des poètes - en critiquant au passage les esprits à la religion étroite (religiosuli) qui associent l'amour au vice - et s'achève sur l'énumération de tous les savoirs que contient l'œuvre de Térence : science militaire, économie domestique, philosophie, science des augures, physiognomonie, géographie, sans oublier la médecine, le droit et la théologie. Étudier Térence est utile, non seulement pour former la jeunesse à la langue latine et à l'art oratoire, mais pour donner aux futurs citoyens, à côté des rudiments des sciences, une idée juste des devoirs de la vie civile et de la piété. C'est donc sur une exhortation à lire ses comédies que se conclut cette épître dédicatoire, qui offre un reflet fidèle du prix que l'on accordait à Térence dans les milieux évangéliques allemands dans la première moitié du Xvi ${ }^{\mathrm{e}}$ siècle.

\title{
ÉP̂TTRE DÉDICATOIRE
}

\section{Gregor Wagner de Reszel \\ à un adolescent prometteur, Josse Willich le jeune, fils de son frère ${ }^{4}$}

\author{
EPISTOLA DEDICATORIA \\ Optimae spei adolescentulo Iodoco Vuillichio iuniori sui fratris filio, Gregorius Vuagnerus \\ Resellianus, S. P. D. ${ }^{5}$
}

1 Sont dignes de mémoire et d'éloge, excellent Josse, les efforts des critiques pour comprendre l'économie de tout discours, si la parole est «la reine du monde ${ }^{6}$ »: ils mobilisent toutes leurs capacités d'attention ${ }^{7}$ pour l'étudier chez les bons auteurs et, par honnêteté intellectuelle, communiquent généreusement leurs découvertes sur l'art qui y est caché. Heureuse décision de leur part ! Car aux ignorants, ils montrent ainsi la voie pour méditer de façon similaire sur toute sorte d'écrits : un jour enfin, à force de lire et de relire les grands auteurs, ces mêmes ignorants pourront en tirer un profit à jamais chérissable, les comprendront mieux et porteront un jugement plus exact sur leurs beautés.

Commemorandus et magnifaciundus est eorum conatus, optime Iodoce, qui oeconomiam orationis, rerum reginae, in bonis authoribus obseruatam, imis sensibus reponunt, et pro animi sui candore, artificii eliciti notationem aliis humaniter communicant. Nam 
secundissima hac uoluntate, rudioribus fenestram ad summam cogitationum similium, in omni genere scripti, faciendam, aperiunt, ut tandem aliquando et isti, in authoribus perlegendis, fructus non poenitendos faciant, eos melius intelligant, rectiusque de illis iudicium ferant.

On sait bien que la plupart des auteurs illustres ont mis tout leur soin à témoigner dans leurs écrits de la force de la disposition, à conserver le bon ordre (eutakta) et à éviter et proscrire absolument les mauvais arrangements (anoikonomèta) que condamnent au plus haut point les Dialecticiens et les Rhéteurs ${ }^{8}$. Certes, le discours fait briller la matière elle-même par les différentes figures de mots et de pensées, mais je suis d'avis qu'il faut accorder beaucoup à la forme de la disposition, qui lui donne son assise. C'est elle, en effet, qui fait toutes choses plus expressives et plus brillantes. Elle rend le lecteur ou l'auditeur plus pénétrant et plus habile en termes d'invention et de jugement ${ }^{9}$. Elle est cause, je crois, de ce que les Rhéteurs ont assigné à la disposition la première place après l'invention entre les parties du discours, parce qu'elle est distribution des matières, qu'elle indique pour chaque passage ce qui convient et ce qu'il faut y placer. En lui attribuant ce rang, ils ont montré sans ambiguïté qu'il faut en toutes choses faire le plus grand cas de l'arrangement lui-même. C'est lui, dis-je, qui apporte beaucoup de lumière et suscite beaucoup d'admiration à l'oral comme à l'écrit ; si au contraire on le néglige, il provoque une confusion extrême.

Notum est, quod plerique omnes illustres authores summo studio sint enixi, ut in scriptis suis

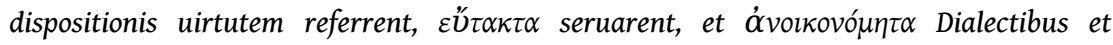
Rhetoribus ad extremum damnata, prorsus deuitarent atque excluderent. Equidem cum oratio res ipsas uariis luminibus uerborum et sententiarum exornet, multum in dispositionis forma, cuius beneficio illa stare uidetur, ponendum esse censeo. Facit enim ut omnia expressiora et illustriora habeantur. Reddit lectorem uel auditorem acutio0072em, atque habiliorem in inueniendo et diiudicando. Hanc reor esse caussam, quod Rhetores post inuentionem dispositioni, quae est distributio rerum, quae demonstrat, quid quibus locis conueniat, aut collocandum sit, inter partes orationis, primum locum assignarunt. Qua uero loci attributione, non obscure ostenderunt, ipsius collocationis in omnibus rebus summam habendam esse rationem. Haec, inquam, est, quae multum lucis et admirationis in loquendo et scribendo adfert, e contra neglecta maximam confusionem parit.

3 Sur ce sujet, Quintilien nous a laissé ces mots: "Les membres, déplacés même légèrement, perdent la fonction qui faisait leur valeur, et les armées en désordre sont pour elles-mêmes une grande gêne. Et je crois qu'ils ne se trompent pas, ceux qui pensent que la nature même de l'univers se maintient par l'ordre; que, s'il cédait à la confusion, tout périrait. De même, le discours qui manque de cette qualité, s'agite nécessairement à l'aventure, flotte sans méthode, n'a aucune cohérence, se répète beaucoup, change souvent de sujet, comme un homme errant la nuit dans des territoires inconnus, et, sans début ni fin, suit le hasard plutôt qu'une résolution ${ }^{10}$.» Dans ce texte, la nécessité manifeste de l'ordre est indiquée par deux images (similitudo). La première est empruntée au corps humain : nous constatons d'expérience que, si un membre est enlevé du lieu où la nature l'a placé, il n'est plus d'aucun usage ; bien plus, on le tient pour mutilé et inutile. La seconde est tirée d'une armée qui, rangée en bon ordre, se sort de situations critiques, souvent désespérées, comme on le voit clairement dans la seule défaite de Tarente ${ }^{11}$; il est évident au contraire que des troupes en désordre causent leur propre ruine. De même, la composition du discours, si elle n'est organisée selon une disposition adaptée, suit une route hasardeuse et prouve plutôt l'impétuosité de celui qui parle que la qualité de sa stratégie d'ensemble (consilium). On se moquerait d'un Architecte qui édifierait son ouvrage en amassant des pierres, du bois, du mortier et toutes choses utiles aux constructeurs, sans appliquer 
son art à les disposer et à les arranger ensemble. On jugerait de la même façon bien peu avisé l'orateur ou l'écrivain, qui, bien qu'affichant un lexique brillant, des pensées fortes et de bons arguments, ne mettrait pas chaque élément à sa juste place et ne construirait pas selon le bon ordre (eukosmôs) l'enchaînement des parties du discours. Je te l'affirme, et la chose est on ne peut plus assurée, le corps tout entier d'un discours, tout excellent qu'il soit, perd sa grâce et tombe hors de propos (ouden pros epos) s'il a négligé l'appareil de la disposition. Et personne n'ira contester que, même seul, un arrangement adapté sert excellemment la mémoire de l'enseignant comme de l'élève, la développe et l'entretient. La chose est donc digne qu'on y consacre son énergie et qu'on la tienne pour bien préférable à l'argent et à l'or.

De qua sic Quintilianus scriptum reliquit : Artus, inquit, etiam leuiter loco moti, perdunt, quo uiguerunt, usum, et turbati exercitus sibi ipsis sunt impedimento. Nec mihi uidentur errare, qui ipsam rerum naturam ordine stare putant, quo confuso, peritura sint omnia. Sic oratio carens hac uirtute, tumultuetur necesse est, et sine ratione fluctuet, nec cohaereat sibi, multa repetat, multa transferat, uelut nocte in ignotis errans, nec initio, nec fine proposito casum potius quam consilium sequatur, haec ille. Euidens huius uirtutis necessitas hic duabus similitudinibus commonstratur. Quarum prior a corpore humano est desumpta, ubi re ipsa experimur, quando membrum aliquod naturali loco semotum fuerit, nullius rei usui esse, imo mancum et inutile haberi. Posterior ab exercitu, qui iusto ordine constitutus rerum discrimina, in summa desperatione saepe depellit, ut patet in una Tarentina clade, et contra turbatas inuicem copias exitio sibi fuisse constat. Ita orationis compositio, nisi apta contexatur dispositione, sine ratione fluctuaret, dicentisque impetum potius, quam consilium argueret. Ridiculus esset Architectus, opus extruens, si saxa, ligna, caementa, et caetera aedificantibus utilia conferret, nisi disponendis eis, collocandisque artificium adhiberet. Sic et orator seu scriptor parum prudens iudicaretur, etiam si uerba praeclara, sententias graues, et argumenta firma in promptu haberet, si non singula in suum locum et

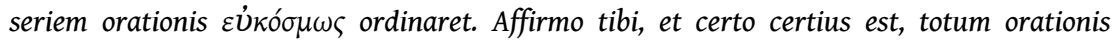

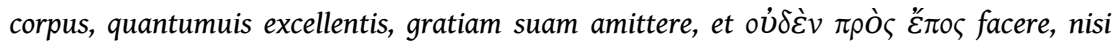
dispositionis ornamentum accesserit. Neque ullus inficias ibit, quod uel sola apta collocatio memoriae tam docentis quam discentis, plurimum inseruiat, augeat, et foueat. Digna igitur res est, ubi quis neruos intendat suos, eamque auro et argento longe potiorem habeat.

4 Les Auteurs comiques ont pensé de même, puisqu'ils disposent leurs pièces (dramata) en prologue (prologos), protase (protasis), épitase (epitasis) et dénouement (catastrophè). Chez Térence, le prologue est tantôt sustatique (sustatikos), quand on recommande la pièce ou le poète au spectateur ${ }^{12}$; tantôt anaphorique (anaphorikos), lorsqu'on adresse à un adversaire des propos malveillants; tantôt mixte (miktos), quand il participe des deux précédents ; mais il a valeur d'exposition (hupothetikos), lorsqu'on y présente le sujet de la pièce, type de prologue plus familier à Plaute. Dans la protase, qui ouvre l'action avec en quelque sorte la mise en route des premiers troubles, on traite d'abord de la circonstance de la pièce et de son sujet; puis on représente les projets des vieillards, leurs sérieuses pensées adaptées aux circonstances, les issues inattendues des projets, les querelles et passions violentes, les trahisons des esclaves, les amours des jeunes gens, les séductions des femmes légères. Dans l'épitase, où l'agitation atteint son comble, l'histoire se complique: on saisit les méprises qui bouleversent tous les personnages, les gestes et les visages troublés, et on montre par là le nœud de l'action (tou dramatos stasis). Et c'est ainsi que dans le dénouement, qui est un retournement imprévu des événements jusqu'à l'issue heureuse de l'intrigue, tous les personnages sont jetés dans une joie inespérée et toutes choses s'apaisent ${ }^{13}$. D'où l'expression proverbiale : «la fin de la comédie », pour l'issue de quelque événement que ce soit ${ }^{14}$. Ajoutons que, sous ces trois parties de la Comédie, sont compris cinq actes, selon les termes d'Horace : «Une longueur de cinq actes, ni plus ni moins ${ }^{15}$ », etc. Le mot acte est 
tiré du verbe agere, «jouer, représenter », il désigne un laps de temps déterminé du jeu de la Comédie qui se déroule sans interruption, jusqu'à ce que la scène soit vide de personnages. Dans l'intervalle, on joue de la Musique pour l'agrément et la récréation des auditeurs ${ }^{16}$. D'où l'expression : «ajouter le dernier acte à la pièce ", c'est-à-dire y mettre le point final ${ }^{17}$.

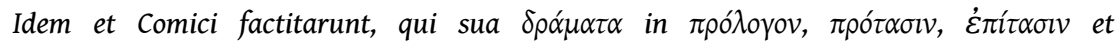

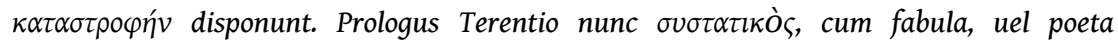

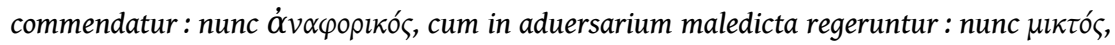

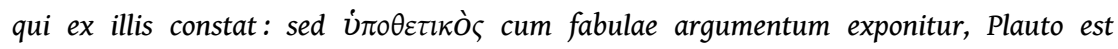
familiarior. In protasi quidem, quae est initium actionis, cum primo illo tumultu iam quasi gliscente, fabulae occasio et argumentum tractatur, item senum consilia, graues pro tempore sententiae, consiliorum inopinati euentus, uehementes querelae et affectus, seruorum perfidia, amores adolescentum muliercularum lenocinia, depinguntur. Sic in epitasi, turba feruentissima, argumentum implicatur, errores, magna cum personarum omnium

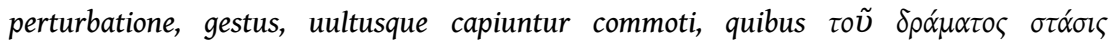
ostenditur. Sic et in catastrophe, quae est subita rerum ad iucundos rei institutae exitus conuersio, omnes personae in laetitiam insperatam coniiciuntur, et fit rerum omnium tranquillitas. Hinc abiit in prouerbium : Catastrophe fabulae, pro cuiuslibet rei exitu. Porro sub his tribus Comoediae partibus continentur quinque actus, iuxta illud Horatianum: Nec sit quinto productior actu, etc. Dicitur ab agendo, et est certum spacium actae Comoediae sine intermissione, theatro a personis uacuo relicto. Interim Musica in auditorum gratiam et recreationem adhibetur. Hinc phrasis orta est, supremum actum fabulae addere, est extremum finem ponere.

5 Prenons un exemple: le premier acte développe l'argument comme nous le voyons dans L'Andrienne. Exposant l'argument de la pièce, Simon dit son intention de recourir à des noces fictives pour avoir une cause réelle de faire des reproches à son fils. Dave délibère pour s'opposer aux menaces du vieillard. Pamphile, une fois au courant $d u$ projet de mariage, se plaint amèrement de son père et de Chrémès, parce qu'ils ne lui en ont pas parlé. Au second acte commence vraiment l'intrigue. Charinus cherche à empêcher Pamphile d'épouser Philumène que lui-même désire; Pamphile s'apaise, ce que Dave rend vraisemblable en apportant la preuve que les noces sont simulées. Il convainc donc Pamphile de ne pas refuser le mariage quand son père l'y pousse. Byrrhia entend cela, il en est bouleversé pour son maître Charinus. Dave rassure Simon qui doutait jusqu'ici du consentement de Pamphile au mariage, et c'est vers là que tend la protase de la Comédie. Le troisième acte voit l'agitation croître: l'intrigue se complique et tous les obstacles surgissent. Simon pense que l'accouchement de Glycère est simulé, il se trompe, mais persévère dans cette idée malgré les efforts de Dave pour le persuader. C'est donc plein de trouble qu'il demande en mariage la fille de Chrémès pour son fils, décidé à poursuivre sérieusement l'entreprise. Le désarroi de Dave et de Pamphile est terrible, c'est le début de l'épitase. Le quatrième acte montre le moment dans l'épitase où la situation semble désespérée et, à la fin, apporte la circonstance qui fait le dénouement. Charinus s'indigne contre Pamphile parce qu'il n'a pas tenu parole. Les amants sont terriblement inquiets. Parce qu'il a exposé l'enfant sur le seuil de la demeure de Simon, Dave empêche Chrémès de donner sa fille à Pamphile, dont le cœur est pris ailleurs, mais au dernier moment, arrive l'étranger Criton comme ex machina (apo tès mèkhanès). Le cinquième acte apporte un remède aux grands chagrins, exauce les vœux de tous les personnages et les remplit d'une joie extrême. Chrémès fait des reproches à Simon et refuse les noces à cause de l'enfant de Glycère. Quand Dave déclare que, d'après le récit de Criton, Glycère est citoyenne athénienne, il est jeté dans les fers. Pamphile est violemment pris à partie par son père - c'est le point culminant 
de l'épitase - jusqu'à ce que Criton lui-même, homme de valeur, montre, détails circonstanciés à l'appui, que Glycère est la fille de Chrémès. Pamphile l'obtient, et Philumène épouse Charinus ${ }^{18}$. C'est ainsi que toute l'affaire est menée à sa résolution et que le calme revient ${ }^{19}$.

Exempli gratia, ut, Primus actus argumenti explicationem continet, ueluti in Andria Simo fabulae argumentum exponens, consilium intendit, ut per falsas nuptias, uera obiurgandi filium sit caussa. Dauus aduersus minas senis deliberat. Pamphilus cognito nuptiarum consilio, de patre et Chremete, quod illi rem non communicauerint, grauiter conqueritur. Secundus, ingressum fabulae declarat. Charinus agit cum Pamphilo, ne cupitam Philumenam ducat, acquiescit Pamphilus, quod Dauus uerisimile reddit, simulatas nuptias probans. Ideo suadet Pamphilo, ne patri urgenti nuptias, repugnet. Hoc ubi Byrrhia audit, uice Charini heri sui, perturbatur. Dubitantem adhuc Simonem de consensu Pamphili in nuptias, confirmat Dauus, eo Comoediae protasis spectat. Tertius habet progressionem turbarum, cum argumenti implicatione et omnium difficultatum commotione. Simo partum Glycerii simulatum putat, in errore, Dauo suasore persenerat. Hac de caussa commotus, Chremetis filiam, suo filio uxorem poscit, rem seriam aggressurus. Perturbantur mirum in

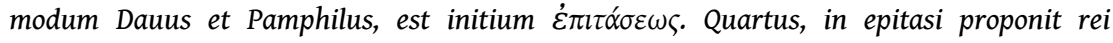
institutae desperationem, et in fine sumitur occasio catastrophes. Indignatur Charinus Pamphilo de fide non seruata. Amantes sollicitantur mirifice. Dauus deterret Chremetem, exposito puero ante aedes Simonis, ne det filiam suam Pamphilo in alieno amore occupato, sed hospitis Critonis interuentus $\dot{\alpha} \pi \dot{o} \tau \tilde{\eta} \varsigma \mu \eta \chi \alpha v \tilde{\eta} \varsigma$ in extremis adest. Quintus magnis aegritudinibus remedium adfert, omnes personas uoti compotes reddit, et summo gaudio explet. Chremes cum Simone expostulat, et ob natum ex Glycerio filium, nuptias recusat. Vbi Dauus ex Critonis relatione Glycerium ciuem Atticam pronunciat, in uincula coniicitur. Pamphilus uehementer dictis paternis confutatur, hic est summa epithasis, donec Crito ipse, homo quantiuis pretii, ex circunstantiis, Glycerium esse filiam Chremetis edocet. Hanc Pamphilus obtinet, et Philumena Charino sit coniunx. Ita omnis res in tranquillum deducitur.

6 Au reste, l'acte, quel qu'il soit, a plusieurs scènes, mais leur nombre n'est pas fixé. En général, on en met, à sa guise, cinq, six, sept, huit, tout au plus neuf. La scène, skènè pour les Grecs, désigne la tente que l'on dresse en un lieu pour les représentations : l'acteur se tient à l'intérieur, et il en sort pour faire le spectacle. On procède ainsi pour éviter la confusion des personnages, tout à fait désagréable pour les spectateurs. Mais chaque scène, même la plus brève, s'orne, à côté des figures éclatantes de la rhétorique, d'une disposition qui lui est propre, mais dont l'appareil obéit à la dialectique. Par exemple dans L'Andrienne, la scène qui commence par « Dieux bons ${ }^{20}$ ! " est une scène de consolation, qui relève de l'état conjectural : il s'agit de savoir si les noces auront lieu ou non ${ }^{21}$. L'exorde (exordium) est tiré d'une joie inespérée. Qu'on apporte une bonne nouvelle sert à susciter l'intérêt (attentio) ; qu'on dise " tu redoutes de ne pas l'épouser, et toi de l'épouser » rend les choses faciles à comprendre (docilitas) ${ }^{22}$. La proposition (propositio) est: les noces n'auront pas lieu. Suit la confirmation (confirmatio) par le moyen d'une accumulation de sept indices ou conjectures ${ }^{23}$ : le peu de victuailles, la tristesse de Simon, la présence de Chrémès, seul, devant sa porte, personne n'entre ni ne sort, nulle maîtresse de maison dans la demeure, aucun préparatif, des légumes et quelques petits poissons achetés pour une obole pour le dîner du vieil homme. Conclusion : les noces sont sans fondement, elles n'ont aucune valeur. Autre exemple, tiré de l'Heautontimoroumenos: Clinias revenu d'Asie soupçonne son Antiphila d'être débauchée. Syrus, avec une très grande habileté, lui ôte ce soupçon ${ }^{24}$. Proposition : la vie d'Antiphila n'a pas changé et son cœur envers toi est resté le même. Il confirme cette proposition par un exposé des faits (narratio) où il expose (narrans) les indices de son honnête conduite. Il donne comme premier indice, la compagnie laborieuse dont 
elle s'entoure. Car lorsqu'il a été envoyé pour la chercher avec Dromon, les portes, ditil, ont tout de suite été poussées ; « une vieille femme s'est avancée qui, lorsque la porte a été ouverte, » est aussitôt retournée à sa laine et tissait son fil. Deuxième indice : sa manière de vivre habituelle - « Nous sommes arrivés à l'improviste chez la femme [...], nous l'avons trouvée tissant sa toile avec soin » - parce qu'on ne l'a pas trouvée oisive mais en train de travailler. On dit chez Tite-Live la même chose de Lucrèce, parangon de la pudeur romaine, parce que Collatin et les autres Romains l'avaient trouvée au milieu de ses servantes en train de filer la laine de sa quenouille ${ }^{25}$. Troisième indice : le peu de soin de sa parure : elle est "vêtue d'une robe simple et triste ", elle n'a pas " de bijoux d'or ", elle n'est pas fardée pour des amants, ses cheveux sont épars, en désordre et « rejetés négligemment tout autour de sa tête ». Quatrième indice : la pauvreté de sa domesticité : elle n'avait qu'une servante, «négligée et couverte de crasse ». Cinquième indice : la saleté de ses messagers : ils sont négligés, ce qui est aussi un indice fort que la maitresse n'a pas commis de faute. Enfin, dernier indice, le désir qu'elle a de toi : " quand nous avons dit que tu étais revenu et que tu lui demandais de venir, la femme a laissé sa toile à l'instant et son visage s'est rempli de larmes, etc. »Conclusion : ton Antiphile est donc la même, et elle n'est pas débauchée. Tu trouveras chez notre Comique plusieurs exemples de cette façon de persuader et de l'ordre qu'il faut y mettre, mis en lumière par les règles des Dialecticiens et des Rhéteurs autant que jamais. De fait, si l'on cherche pour ces règles des exemples familiers (sans eux, elles sont froides) et comme vivants, soit pour bien raisonner soit pour bien parler, on les trouvera chez Térence : avec ses exemples, on saisira plus facilement qu'avec de longs discours la pratique des règles qui relèvent des premiers arts ${ }^{26}$, au point d'offrir sans effort (akoniti) à l'élève qui maîtrise mal les règles, une connaissance de l'art que Plaute ne fournit pas aussi bien ${ }^{27}$.

Caeterum in quolibet actu suae sunt scenae, sed incerto numero. Communiter autem quinque, sex, septem, octo, ut plurimum nouem, pro arbitrio statuuntur. Scena Graecis

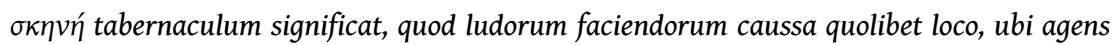
consistat, moueaturque, spectaculum sui praebiturus, ponitur, ne personarum fiat confusio, ipsis spectatoribus admodum ingrata. Verum omnibus in scenis etiam breuissimis sua sunt cum Rhetoricis splendoribus dispositionis ornamenta, sed dialecticw̃s posita, quod genus est in Andria. (Dii boni) est scena consolatoria, in statu coniecturali. An nuptiae sint futurae. Exordium est ab insperata laetitia. Cum aliquid boni portatur, est attentionis, cum dicitur : id paues, ne ducas tu illam, tu autem ut ducas, est docilitatis. Propositio. Nuptiae non sunt futurae. Sequitur confirmatio per congeriem septem signorum seu coniecturarum, paululum obsonii, tristitia Simonis, solitudo ante ostium Chremetis, nemo intrat neque exit, nulla matrona in aedibus, nullus ornatus, olera et pisciculi pauci, coempti obolo in coenam seni. Conclusio. Nuptiae igitur non cohaerent, sunt infirmae. Aliud ex Heauton. ubi Clinia ex Asia reuersus, Antiphilam suam corruptam suspicatur, Syrus eam suspicionem artificiosissime tollit. Propositio. Antiphilae uita eadem est, et animus erga te idem fuit. Hanc narratione confirmat, signa pudicitiae narrans. Primum est, a sodalicio laborioso. nam cum Dromone pro illa accersenda missus, dicit quam primum fores pulsarentur: anus quaedam prodit, haec ubi aperuit ostium, statim ad lanam rediens subtegmen nebat. Secundum, a more uitae quotidianae, ubi de improuiso interuentum est mulieri, texentem telam studiose ipsam offendimus, quia non ociosa sed laboriosa inuenta est. Idem de Lucretia duce Romanae pudicitiae scribitur apud Liuium, quod eam in medio ancillarum pensa de colo ducentem Collatinus et caeteri Romani inuenissent. Tertium, ex ornatu neglecto, quia mediocriter uestita ueste lugubri, quia sine auro ornata sibi, non amatoribus quia non fucata, non caerussata, quia capillo passo, prolixo, circum caput reiecto negligenter. Quartum, a paucitate familiae, quia una ancilla erat, neglecta, immunda illuuie. Quintum, ex sorditie internunciorum, cum hi negliguntur, magnum quoque signum est, dominam esse extra noxiam. Vltimum, a desiderio tui, quia, ubi dicimus, te redisse, et rogare uti ueniret ad te, 
mulier telam deserit continuo, et lacrumis opplet os totum sibi etc. Conclusio. Igitur tua Antiphila eadem est, et non corrupta. Huius loci atque ordinis in hoc nostro Comico, exempla plurima, Dialecticis et Rhetoricis praescriptionibus ita ut cum maxime illustrata, inuenies. $V t$ si quis suorum praeceptorum, uel in arte disserendi, uel benedicendi exempla familiaria (sine quibus illa frigent) et quasi uiua requirat, habebit, quibus usus praeceptionum de primis artibus facilius quam in longiusculis orationibus perspiceretur adeoque mediocriter

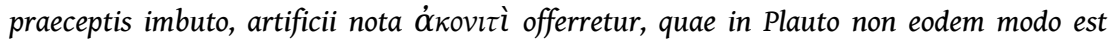
obuia.

7 S'ajoute aussi la propriété dans l'emploi des termes latins, laquelle tient le premier rang dans le discours, que l'on considère les locutions ou les mots pris isolément. Exemples de locutions : accepter une liaison (conditionem accipere, And. 79), payer de mots (dare verba, And. 211), se rendre aux funérailles (in funus prodire, And. 115), rendre service à quelqu'un (ab aliquo gratiam inire, Eun. 557), revenir dans le droit chemin (in viam redire, And. 190), être en état de conseiller (consilii locum habere, And. 320), avoir des moyens d'aider ([habere] auxilii copiam, And. 320), se disputer (commutare verba, Phorm. 638), songer à l'intérêt commun (in commune consulere, And. 548), ramener un cœur à la pitié (reducere animum ad misericordiam, And. 559), se dégager des maux (e malis emergere, And. 562), recevoir le prix de sa sottise (pretium ob stultitiam ferre, And. 610), tomber dans un malheur (in malum incidere, And. 782), rester l'homme d'autrefois (antiquum obtinere, And. 817), mettre à exécution la faveur promise (beneficium verbis initum re comprobare, And. 824), se souvenir de quelqu'un dans la prospérité (in secundis aliquem respicere, And. 975). Exemples de mots pris isolément: dans L'Eunuque, "Comment? Que s'est-il passé ? Tu ne dis rien ?» [V, 1] car nous taisons (tacere) nos desseins; dans Les Adelphes, "Ah! Il n'a rien passé sous silence», car nous passons sous silence (reticere) nos douleurs ; dans L'Eunuque, " pourquoi te tais-tu? » ; dans Phormion, « Pourquoi te tais-tu maintenant? ", car nous taisons (obticere) ce qui nous fait honte. Autre exemple, dans l' Heautontimoroumenos, «les dix mines qu'il a promis de me donner» [IV, 3], nous les promettons (polliceri) «à un homme libre ${ }^{28}$ »; dans Phormion, « Moi, je ne pardonne pas, je ne promets rien» [v. 1044], nous promettons (promittere) quand on nous demande. Autre terme : dans l'Heautontimoroumenos, «Et il la fera demander » [IV, 5, v. 775], car nous demandons (poscere) impérieusement; dans L'Andrienne, «j'obtiens de bon gré ce que je demande» [II, 6, v. 422], nous demandons (postulare) à bon droit. Dans le prologue de L'Hécyre, "Maintenant, écoutez avec bienveillance ce que j'ai à vous demander ", nous demandons (petere) en priant. Dans les Adelphes, "Mon frère me cause honte et dépit » [III, 3, v. 391-392], honte à cause du fait honteux, dépit à cause de la douleur, etc. Tout cela doit être scrupuleusement rassemblé en son esprit par celui qui aspire au plus haut degré du savoir. On s'accorde, et par un éloge unanime, sur le fait que ce comique latin est un amoureux de la pureté de la langue, le meilleur même, comme l'a appelé Cicéron, ce garant de la latinité qui n'a pas rougi d'imiter Térence et de se le rendre familier au point d'user comme siens de nombreux passages empruntés à son œuvre. Ce poète est utile pour perfectionner sa langue, pour désapprendre la barbarie, pour nourrir l'abondance et la richesse du discours et des sentences, pour trouver des arguments dans tous les genres de cause, enfin pour acquérir la capacité de parler et d'écrire avec talent. Son style est à la fois agréable et parfaitement adapté aux esprits des enfants, aisé, simple, clair, sans rien d'ambigu ni d'affecté ou de prétentieux.

Accedit et sermonis latini proprietas, quae in oratione principatum obtinet, tam in coniunctorum, quam singulorum uerborum, obseruatione. Coniunctorum quidem sunt, accipere conditionem, dare uerba, in funus prodire, ab aliquo gratiam inire, in uiam redire, consilii locum habere, auxilii copiam, commutare uerba, in commune consulere, reducere 
animum ad misericordiam, ex malis emergere, pretium ob stultitiam ferre, in malum incidere, antiquum obtinere, beneficium uerbis initum re comprobare, in secundis aliquem respicere. Singulorum uero sunt, in Eunuch. Quamobrem quod factum est, taces? tacemus consilia, in Adelp. Vuah, nihil reticuit, reticemus dolores, in Eunucho, quid obticuisti? in Phor. hem, quid nunc obticuisti? obticemus quorum nos pudet. Aliud, in Heaut. Decem minas, quas mihi dare pollicitus est, pollicemur ultronei, in Phor. Neque ego ignosco, neque promitto, promittimus rogati. Aliud in Heaut. Et quidem iubebit posci, poscimus imperiose, in And. quum istuc, quod postulo, impetro cum gratia, postulamus iure. In prologo Hecyrae. Nunc quid petam, aequo animo attendite, petimus precario. Aliud in Adelph. fratris me quidem pudet, pigetque, pudet propter turpia, piget propter dolores, et cae. Haec omnia diligenter animo colligenda sunt ad culmen eruditionis aspiranti. Conuenit et communi omnium laude, hunc Comicum puri sermonis esse amatorem, et optimum, ut uocauit eum Cicero, authorem latinitatis, quem non erubuit imitari Terentium, et eundem sibi ita familiarem reddere, ut ex hoc ipso multos locos transsumptos pro suis usurparit. Hic poeta prodest ad expoliendam linguam, ad barbariem dediscendam, ad orationis, sententiarumque copiam et ubertatem, ad argumentorum in omni genere caussarum inuentionem, ad parandam denique dicendi scribendique facultatem. Huius oratio et iucunda est, et maxime accommodata puerorum ingeniis, plana, simplex, perspicua, nihil omnino habens ambiguum, aut ambitiose affectatum.

Crois-moi, cher neveu (ô anepsie), jamais tu ne seras mécontent d'un tel auteur, et assurément, tu consacreras une bonne partie de ton travail et de ton étude à connaître parfaitement ses Comédies. Et si tu veux un jour user et tirer fruit de mon aide sur cette matière, j'y emploierai pour toi mon industrie ; nul embarras ne m'arrêtera, même si je suis très occupé. Car je suis extrêmement redevable à ton très respectable père, mon intime ami, à qui je dois d'avoir sué29 sur les belles lettres : si j'ai quelque science, c'est bien grâce à lui. Il n'épargna aucune peine pour me donner sa science, puisqu'il m'inculqua les rudiments non seulement dans sa demeure mais aussi durant des promenades. C'est la même incroyable affection que tu pourras attendre de ma part, et tout le dévouement, le plus grand et le plus rare, qui est en mon pouvoir.

Hoc meae crede fidei $\tilde{\omega} \dot{\alpha} v \varepsilon \psi l \grave{\varepsilon}$, quod huius authoris nunquam te poenitebit, et quidem plurimum operae ac studii, in huius poetae perfecte cognoscendis Comoediis pones. Quod si aliquando mea opera in hac re uti <et> frui uolueris, solertem tibi dabo, et nulla molestia grauabor etiam occupatissimus. Siquidem tuus pater obseruandissimus, meique intimus de me optime meritus est, cui quod literis insudauerim, et si quid eruditionis in me sit, acceptum refero. Qui in me erudiendo nullum laborem subterfugit, qui me non solum domi suae, sed etiam inter spaciandum praeceptis imbuit. Eundem incredibilem amorem, et mea omnia in te ipsum, summa ac singularia studia expectabis.

Dès que je suis arrivé ici, c'est Térence qu'il m'a fallu pratiquer en premier. Mon frère ne voulut pas que j'écoute les leçons sur les autres auteurs, les meilleurs, qu'il faisait alors pour ses élèves dans toutes les langues, avant de savoir Térence sur le bout des doigts. Ne te laisse pas persuader sottement qu'il est suffisant d'avoir entendu ses Comédies une fois ou deux. Pense qu'en vérité on ne connait bien Térence qu'après l'avoir lu et écouté très souvent. Il a ceci de singulier, par comparaison avec les autres Comiques, que plus on lit ses Comédies, plus on a envie de les relire et de les connaître parfaitement. Et tous les doctes donnent ce crédit aux Comédies de Térence, qu'ils ne peuvent jamais assez les étudier pour leurs exemples remarquables et leurs sentences, qui les exhortent sans cesse et leur apprennent à considérer plus attentivement les affaires humaines, et à en juger avec plus de sagesse. Il y a dans chaque Comédie de grandes vérités concernant les mœurs diverses des hommes, leurs naturels et leurs devoirs, très utiles pour régler sa vie en sage et en bon citoyen. "Et en effet ", dit Cicéron dans son plaidoyer pour Roscius, «je pense que ces fictions ont été conçues par 
les poètes pour que nous puissions voir dans des personnages étrangers la peinture de nos mœurs et leur image vive ${ }^{30} »$. C'est pourquoi il a défini la Comédie avec éloge (kat'epainon) comme « une imitation de la vie, un miroir de l'usage, une image de la réalitée $^{31}$ ». Car elle recommande les vertus et s'acharne contre les vices et, pour n'importe quel âge, sexe, ou condition, offre des situations concrètes où exercer la $v^{v e r t u}{ }^{32}$. C'est la représentation de presque toutes les actions privées que l'on voit ici, et un modèle bien dessiné. C'est ce qu'évoque Déméa dans Les Adelphes : «Je l'invite à regarder comme en un miroir les vies des hommes et à prendre sur autrui exemple pour $\mathrm{soi}^{33} »$.

\begin{abstract}
Quamprimum huc pedem tuli, primus author Terentius erat terendus mihi. Noluit prius frater, reliquos authores, quos tum optimos suis discipulis, in omnibus linguis praelegit, me audire: quam in hoc bene uersatus essem; Nec sinas te abduci stulta illa persuasione, quasi omnino satis sit Comoedias Terentianas semel atque iterum audisse. Id quod res est, existima, tum demum Terentium feliciter cognosci, ubi saepissime et lectus, et auditus fuerit. Qui prae caeteris Comicis hoc habet singulare, ut quo saepius legantur Comoediae, eo magis incitent animum ad easdem saepius relegendas ac perfecte cognoscendas. Et tribuunt omnes eruditi hoc Terentianis Comoediis, quod satis eas legere nunquam possint, propter egregia exempla et sententias, quibus admoniti subinde discant diligentius considerare res humanas, et prudentius de illis iudicare. Sunt in singulis Comoediis certae quaedam theses de hominum diuersis moribus, ingeniis, et officiis propositae, quae multum faciunt ad uitam sapienter et ciuiliter instituendam. Etenim, inquit Cicero pro Roscio, haec conficta arbitror a poetis esse, ut effictos nostros mores in alienis personis, expressamque imaginem uideremus. Ideo $\kappa \alpha \tau \tau^{\prime}$ ' $^{\prime} \alpha$ lvvov Comoediam definiuit, quod sit uitae imitatio, speculum consuetudinis, imago ueritatis. Commendat enim uirtutes, et uitia insectatur, et in qualibet aetate, sexu et conditione, uirtutis materiam praebet. Omnium fere actionum domesticarum imago et typus expressus hic cernitur. Eo respicit illud Demeae in Adel. Inspicere tanquam in speculum uitas hominum iubeo, atque ex aliis sumere exemplum sibi.
\end{abstract}

Il faut considérer à la fois la convenance (decorum) et le traitement des émotions (tractatio affectuum), que les Grecs appellent èthè $\grave{e}^{34}$ : celui qui les aura scrupuleusement observés en deviendra bien plus avisé et il n'arrivera jamais qu'il n'en sorte pas plus savant. Mais pour qu'on distingue tout cela plus clairement, sont toujours, comme dans un miroir, diamétralement opposés par leurs mœurs différentes les vieillards, les jeunes gens, les esclaves, les femmes légères, etc. Ainsi dans L'Andrienne, Simon l'irascible est opposé à Chrémès dont l'âme est tranquille et placide; Pamphile le réservé est opposé à Charinus, téméraire et ignorant; l'habile et astucieux Davus s'oppose à Byrrhia qui est paresseux et malhabile ; Mysis la sobre s'oppose à Lesbie qui est ivre; Criton est pauvre et honnête quand Chrysis est riche et malhonnête. Le poète fait cela de propos délibéré, pour que « les éléments contraires, disposés les uns à côté des autres brillent davantage ${ }^{35} »$. On ne peut dire à quel point ce peintre des mœurs est ici remarquable et unique en son genre, pour tous les caractères propres des personnages dressés selon la convenance (to prepon) et d'ailleurs, si admirable que les mots et les lettres représentent les émotions des personnages eux-mêmes. Prenons par exemple la tirade de Géta, enflammé de colère parce que Eschine a indignement déshonoré et violé Pamphila : «Et puis, Syrus l'instigateur, ah! de quelles manières je le mettrais en pièces! Je l'attraperais par le milieu du corps pour le soulever et lui écraserais la tête au sol pour qu'il répande sa cervelle sur la route; au jeune homme, j'arracherais les yeux, après quoi je le précipiterais la tête la première. Les autres, je les culbuterais, houspillerais, bousculerais, assommerais et aplatirais ${ }^{36} ! »$ Dans ce passage, on trouve partout la lettre qui mord, le $\mathrm{R}$, très fréquent chez les hommes en colère ${ }^{37}$. Une telle attention aux figures instruit de la vie des hommes, et en même temps sert à 
l'éloquence. Par conséquent, il est possible d'inscrire dans un cœur l'éclat des vertus, et en plus de les jouer au théâtre ${ }^{38}$, tout en expulsant du même cœur la puanteur des vices et en les condamnant d'une haine éternelle. « Connaître tout cela, c'est le salut pour les tout jeunes gens ${ }^{39}$. » Aucun d'eux ne sera si lourdaud, si stupide, si sot que, à lire ou à voir jouer ces Comédies, ou à suivre les cours sur Térence, il fasse autre chose - je le dis franchement et fermement - que de prendre parti pour le meilleur et le plus digne de louange ${ }^{40}$.

Intuendum est et decorum et tractatio affectuum, quae Graecis sunt $\ddot{\eta} \theta \eta$, quae si quis diligenter obseruauerit, multo prudentior euadet, et nunquam accedet, quin abiturus sit doctior. Verum ut haec omnia clarius conspiciantur, tanquam in speculo, ex diametro semper opponuntur diuersis moribus senes, adolescentes, serui mulierculae, etc. Sicut in Andria est uidere. Simo iracundus opponitur Chremeti placido et sedato animo. Pamphilus uerecundus Charino temerario et rerum imperito. Dauus astutus et callidus Byrrhiae ignauo inerti. Mysis sobria Lesbiae temulentae. Crito honeste pauper Chrysidi inhoneste diuiti. De industria hoc fit a poeta, ut opposita iuxta se posita magis elucescant. Dici nequit quam

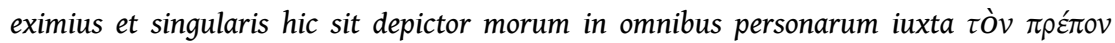
proprietatibus atque adeo, ita admirabilis, ut uerba et literae ipsissimum personarum affectum representent. Sit exemplo illud Getae, qui ira inflammatus, quod Aeschinus Pamphilae indigne per uim uitium obtulerat. Tum autem Syrum impulsorem, uah, quibus illum lacerarem modis. Sublimem medium arriperem, et capite primum in terram statuerem, ut cerebro dispergat uiam. Adolescenti ipsi eriperem oculos, posthac praecipitem darem. Caeteros ruerem, agerem, raperem, tunderem, et prosternerem. Hic ubique litera canina inseritur, iratis multo familiarior. Talis figurarum obseruatio, simul et de uita hominum monet, et conducit ad eloquentiam. Proinde integrum est, uirtutum splendorem in animo scribere, adeoque imitatione repraesentare, et uitiorum foetorem ex eodem expuere et perpetuo odisse. Nosse omnia haec, salus est adolescentulis. Quorum nemo tam plumbeus, stupidus et insulsus erit, qui ex lectione uel actione Comoediarum, sicut in publica huius Comici lectione, sedulo et fideliter moneo, quod optimum et laude dignissimum uidebitur, sibi non eligeret, sequereturque.

11 Et maintenant, toutes ces Comédies, parce qu'il souhaitait que personne ne se détourne de cet auteur comique, le très illustre et très savant Willich, honneur et lumière perpétuels de notre famille, d'une manière on ne peut plus claire et limpide grâce à sa riche sagesse, les a éclairées et éditées conformément à ce que nous attendions, si bien que je ne vois rien à désirer en ce qui concerne la disposition, le style et la difficulté de certains passages. Bien qu'il nous ait fait ces scholies à la hâte, et pour le plaisir de son esprit, le lecteur diligent sentira cependant que rien ne gêne l'enchaînement continu (sunepeia ${ }^{41}$ ) des mots, rien n'est compliqué, tout coule de source. Il faut le dire, j'ai souvent admiré, et tous les auditeurs avec moi, l'intelligence naturelle de son esprit lorsqu'il s'agissait de repérer la visée des auteurs qu'il nous expliquait; de même tous les textes qu'il a édités font connaître le maître illustre. Je ne veux pas flatter ses oreilles et façonner mon discours pour lui plaire (je le sais homme très hostile à la lignée des Gnathon et des Thrason ${ }^{42}$ ). Mais il est hors de doute qu'il le céderait à grand peine à un autre en ce qui concerne la disposition du discours. C'est une chose admirable comme il observe toutes choses avec le plus grand jugement, et pour ainsi dire, un œil de lynx.

Nunc uero haec uniuersa, ne quid scrupulo si ab hoc Comico quenquam absterreret, dilucidissime et pingui Minerua, apertissime, clarissimus et doctissimus Vuillichius nostrae familiae perpetuum decus et lumen, ita perlustrauit, et pro uotis nostris edidit, ut nihil desiderari uideam, quod ad dispositionem, eloquutionem, et locorum quorundam difficultatem spectat. Quamuis opera tumultuaria, et animi gratia, haec scholia nobis

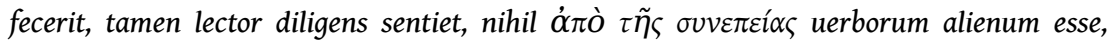


contortum et aquam haerere. Et quod dicendum sit, saepe demiratus sum et mecum omnes auditores, illius ingenii dexteritatem, in animaduertendis authorum scopis, quos nobis enarrauit, sicut et omnia eius scripta in lucem edita, artificem praeclarum commonstrant. Nolo quicquam illius auribus dare, et ad uoluptatem (noui hominem generi Gnathonico, et Thrasonico infestissimum) sermonem meum fingere. Sed indubitatum est, quod uix ulli in disponendae orationis uirtute cederet. Mirum est, ut omnia summo cum iudicio obseruet, et quasi lynceis oculis inspiciat.

12 Et en effet, si l'on désire que l'effort soit moindre, il faut poser les fondements dès la première enfance, pour qu'ils s'affermissent à l'âge adulte, selon le mot de Virgile : "C'est beaucoup de prendre de bonnes habitudes quand on est jeune ${ }^{43}$." Car ce que nous avons observé dans notre jeunesse, reste fixé en nous plus solidement, comme Horace l'a chanté : «Le parfum dont le vase de terre encore neuf s'est une fois imprégné, il le conservera longtemps ${ }^{44}$." Platon aussi soutient que ceux qui sont destinés à devenir un jour des hommes de premier plan doivent commencer à étudier dès l'enfance ${ }^{45}$. Quand les premières années brillent par la douceur des mœurs, on en tire le grand espoir d'une piété future, de même qu'à partir de la vie passée, nous pouvons discerner son cours à venir. C'est ainsi que Cicéron a défendu le jeune Caelius, alors qu'il était appelé en justice pour avoir reçu de l'argent de clodius et du poison préparé par Licinius; il démontre avec fermeté que de telles accusations ne peuvent concerner Caelius. Parce qu'il a été nourri dans les belles lettres depuis son plus jeune âge, il a fui toutes les voluptés, a laissé la recherche du plaisir, a délaissé le théâtre, le jeu, le banquet, la conversation de presque tous ses compagnons. Comme il croissait en âge et en vigueur, il partit en Afrique et prit service auprès des meilleurs; devenu familier du proconsul Pompée, homme tout à fait irréprochable, il se tourna vers la pratique du forum, des affaires, et toute sa vie fut vigilant, sobre, actif et travailleur. Il n'est pas facile à un homme qui a ainsi gouverné sa vie de tomber dans le vice ${ }^{46}$.

\begin{abstract}
Enimuero, ut quis minori negocio eo aspiraret, statim a prima pueritia fundamenta iacienda sunt, quibus adulta aetas corroboraretur, iuxta illud Virgilii. A teneris assuescere multum est. Siquidem ea, quae pueri imbibimus, tenacissime nobis inhaerent, sicut Horatius cecinit : Quo semel est imbuta recens seruabit odorem Testa diu. Ita et Plato asserit eos, qui in praestantes uiros aliquando euasuri sint, ab ineunte statim pueritia oportere studendo incipere. Quum prima aetas morum suauitate clarescit, magna spes futurae pietatis praesumitur, ut etiam ex anteacta uita, reliquum uitae cursum diiudicare possimus. Quemadmodum Cicero Caelium adolescentem defenderit, cum propter pecuniam a Clodio acceptam et paratum uenenum a Licinio in ius uocaretur, firmissime argumentatur, eiusmodi crimina in Caelium cadere non posse. Quia ab ineunte aetate bonis artibus instructus, omnes uoluptates omisit, studia delectationis reliquit, ludos, iocos, conuiuium, sermonem pene omnium familiarium deseruit. Cum paululum roboris accederet aetati, in Aphricam est profectus, optimis quibusque se dedit, utpote Pompeio proconsuli, uiro castissimo factus familiaris, in foro, in negociis uersatus, uigilans, sobrius, industrius, laboriosus, integram uitam semper sequutus. Qui sic uitam suam instituit, non facile in uitia labitur.
\end{abstract}

Les Romains agirent donc avec une extrême sagesse en ne voulant laisser chez les jeunes gens aucune place à l'inaction. Ils ont veillé à éduquer le premier âge aux sciences et aux arts, de même ils se sont accoutumés à la pratique de la parole publique, à la gloire, au mérite, ils ont égalé leurs propres vertus aux louanges des anciens. Alors, naîtra «quelque chose d'éclatant et d'extraordinaire ", quand " une certaine doctrine et une science confirmée se sont jointes à une nature exceptionnelle et illustre ${ }^{47}$ ». De là vient que des hommes habiles ont consacré la plus grande part de leur peine à composer des Comédies, qui en piquant les adolescents comme avec un éperon, leur font rejeter tout désir mauvais. Il est certain que les poètes ont écrit leurs vers sous 
l'impulsion non de leur propre audace mais d'un dieu, par le moyen d'une possession divine (enthousiasmon). Platon l'appelle fureur inspirée par les dieux (entheos), parce que les poètes chantent leurs vers comme transportés (enthousiastai) par l'inspiration d'un dieu ${ }^{48}$. Ovide :

Il est un dieu en nous; il nous agite, il nous échauffe,

Nos transports ont pour source un esprit divin.

Et ailleurs :

Il est un dieu en nous et nous avons commerce avec le ciel,

l'inspiration nous vient des demeures éthérées ${ }^{49}$.

Cicéron déclare dans le Pour Archias que « la valeur du poète réside dans sa nature et qu'il est stimulé par les forces de son esprit, et comme soulevé par une inspiration divine. C'est pourquoi notre grand Ennius qualifie les poètes de sacrés, parce qu'ils sont recommandés auprès de nous par quelque don ou présent divin ${ }^{50}$. " "Tous les poètes, dit-il ${ }^{51}$, chantent leurs illustres poèmes non grâce à une technique mais inspirés par un souffle divin. » On les appelle aussi fils des Dieux. C'est pourquoi ils ne produisent que des chants utiles à la mémoire. Horace :

Les poètes veulent soit être utiles, soit plaire,

Ou, en même temps, dire l'agréable et ce qui sert à la vie ${ }^{52}$.

Prudentissime igitur fecerunt Romani, quod adolescentibus nullum locum ocii relictum uoluerint. Curarunt equidem primam aetatem disciplinis et artibus instituendam, sic ad usum forensem, ad gloriam, ad dignitatem sunt assuefacti, ueterum laudibus suas uirtutes adaequarunt. Tum aliquid praeclarum ac singulare existet, ubi ad naturam eximiam, atque illustrem ratio quaedam confirmatioque doctrinae accesserit. Hinc homines ingeniosi plurimum operae Comoediis scribendis impenderunt, quibus tanquam calcari adolescentes incitati, omnes prauas cupiditates exuerent. Certum est, poetae non temeritate, sed numine

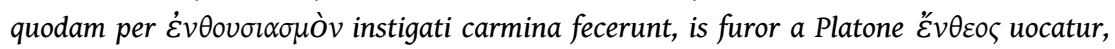

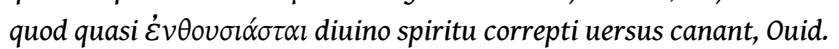

Est deus in nobis agitante calescimus illo

Impetus hic sacrae semina mentis habet.

Idem alibi :

Est deus in nobis sunt et commercia coeli

Sedibus aethereis spiritus ille uenit.

Cicero pro Archia dicit poetam natura ipsa ualere, et mentis uiribus excitari, et quasi diuino spiritu afflari. Quare suo iure noster Ennius ille sanctos appellat poetas, quod quasi deorum aliquo dono atque munere commendati nobis esse uideantur. Omnes, inquit, poetae non arte, sed diuino afflatu omnia ista praeclara poemata canunt. Vocantur et Deorum filii. Igitur non nisi utilia memoriae produnt. Horat.

Aut prodesse uolunt, aut delectare poetae,

Aut simul et iucunda et idonea dicere uitae.

14 Laissons tomber ces hommes à la religion étroite qui disent: ce poète évoque les plaisirs de l'amour (erôtika), il est donc indigne des oreilles pieuses. Voici la réponse à faire : la Bible aussi, tout entière, devrait être rejetée selon l'argument absurde que Dieu les refuse! On y lit des passages plus difficiles à supporter sur l'amour incestueux, quand Ammon fils de David fit violence à sa sœur Thamar et coucha avec elle. Chez Térence sont peints le sort malheureux des amours, leurs souffrances et leurs croix, comme chez les amants que sont Charinus, Chéréa, Phédia, Ctésiphon, troublés à la fois par l'exemple des autres et par la folie; les habiletés des courtisanes, et leurs mœurs qui font mépriser les jeunes gens et les tourmentent de toutes les manières, il les poursuit sans cesse d'une " haine vatinienne ${ }^{53} »$. On objectera que la fréquentation des courtisanes est approuvée par Térence puisque Mition déclare: "Ce n'est pas un scandale qu'un jeune homme fréquente des courtisanes ou boive. » Je répondrai qu'il ne 
dit pas cela du fond du cœur puisqu'il avoue, à la fin de cette scène : « Ces choses-là ne laissent pas de m'être désagréables, mais je n'ai pas voulu lui montrer que je les prenais à cœur ${ }^{54}$. "

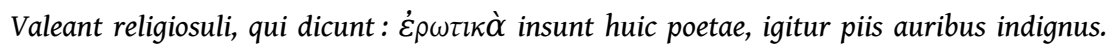
Hoc sibi responsum habeant isti, quod et tota Biblia hoc absurdo argumento, quod Deus auertat, essent reiicienda. Vbi duriores partes in amore de incaestu leguntur, quando Ammon filius Dauid sororem suam Thamar oppresserit, et cubauerit cum ea. Depinguntur hic amorum miserae conditiones, tribulationes et cruces, ut quis amatorum Charini, Chereae, Phaedriae, Ctesiphonis, et aliorum exemplo et insania commotus, meretricum ingenia, et earum mores, quae adolescentiam habent despicatam, et omnibus cruciant modis, Vatiniano quodam odio, perpetuo prosequatur. Obiiciat quis, scortatio a Terentio approbari uidetur, quia Mitio dicit: Non est flagitium adolescentem scortari, neque potare. Respondeo : Haec non ex animo refert, quod in fine illius scenae fatetur, cum inquit : Nonnihil molesta haec sunt mihi, sed ostendere me aegre pati, illi nolui.

Bien plus, outre la logique et l'éthique, il faut examiner avec soin chez notre poète la présence d'autres savoirs, car ils pourraient servir d'aiguillon à une étude plus assidue des lettres. Je te l'assure, c'est un homme plein d'un zèle non commun pour l'ensemble des connaissances qui se laisse voir ici derrière le poète. Je vais convoquer un petit nombre de citations pour rendre compte de son insigne et admirable savoir. Dans L'Andrienne : «Ce que font la plupart des tout jeunes gens, se livrer à quelque passion : élever des chevaux ou des chiens pour la chasse, ou fréquenter les philosophes, etc..$^{55}$ ". En effet, après que Térence "fut sorti de l'éphébie ${ }^{56}$ », ces exercices des tout jeunes gens étaient en vogue, on le voit clairement d'après les Mimes. De fait, l'équitation (hippikè, sous-entendu tekhnè) renvoie au service militaire (dont Cicéron fait l'éloge dans son discours pour Muréna ${ }^{57}$ ), ce que l'instruction militaire de Thrason montre bien, de même le fait qu'il fut lui-même au service d'hommes nobles, P. Scipion et Laelius, et seconda leurs études; de même, la chasse (kunègètikè) renvoie à la gestion des affaires domestiques, par synecdoque (sunekdokhikôs) dans l'Heautontimoroumenos : «Là, tu auras toujours un recours contre ta propre sottise, Clitiphon, la nourriture, le vêtement, un toit pour te recevoir ${ }^{58}$ »; de même, l'art des philosophes renvoie à l'étude des bonnes lettres dans L'Eunuque: « Mets-le à l'épreuve dans les lettres, etc..$^{59}$ ». Il a été un remarquable physionomiste dans l'Heautontimoroumenos: "[cette fille] au visage marqué, au nez busqué ? Je ne peux pas, père ${ }^{60}$. » La couleur rouge est celle d'un homme malfaisant, comme le nez busqué est la marque de l'impudent. Aristote dans la Physiognomonie: "Ceux dont le nez se recourbe au départ du front, les impudents, on les rapproche des cerfs ${ }^{61}$. Il a été habile à rendre des augures, dans Phormion: «Un chien noir étranger est entré dans ma demeure. Un serpent est tombé du toit dans le bassin, une poule a chanté62.» Ce passage demande qu'on soit augure, car les anciens, gagnés à cette opinion, disaient que de tels prodiges étaient présage d'un mariage trop peu heureux. L'entrée d'un chien noir étranger était le signe d'un adultère prochain, la chute d'un serpent du haut du toit annonçait qu'un des époux périrait par le poison. Le chant de la poule, disaient-il, indiquait que le mari serait dominé par l'autorité de sa femme, ce qu'on appelle en grec le gouvernement féminin (gunaikokratia), ou qu'assurément, la femme survivrait à son mari. Il a été un grand médecin, dans Les Adelphes : «Mes membres défaillent de peur, mon esprit est paralysé par la crainte. Mon cœur ne peut se résoudre à rien $^{63}$." Dans la même comédie: "Il a rougi. Tout va $b^{b i e n}{ }^{64}$.» Les philosophes rapportent que la rougeur est signe de pudeur. Dans la même pièce encore : «Il m'écoute volontiers faire ton éloge, je fais de toi un dieu devant lui... Je dis tes vertus... le bonhomme laisse couler ses larmes de joie, comme un enfant ${ }^{65}$." 
Dans L'Eunuque: "Sans Bacchus ni Cérès, Vénus se glace ${ }^{66}$." Car le désir se meurt, lorsqu'il reste sobre. Et encore : "Je tremble et je frissonne quand je la vois ${ }^{67}$." La raison en tient à l'afflux du sang dans les cavités du cœur sous l'effet de la violence du désir; comme il se répand à nouveau, il se produit une chaleur qui est feu au même lieu, prenant sa force dans la vue de son amie. Dans l'Heautontimoroumenos, « la femme laisse sa toile aussitôt et tout son visage se remplit de larmes. Tu aurais bien compris que c'était par amour pour toi ${ }^{68}$ ! ॥ Une joie inespérée arrache souvent des larmes. Qui nierait que Térence a su la Géographie? Dans L'Andrienne: «Il y eut jadis un vieux marchand, il brisa son navire près de l'île d'Andros ${ }^{69}$. " Dans l'Heautontimoroumenos: «quand tu m'as dit que tu avais envie d'une petite servante d'Éthiopie ${ }^{70}$. " Dans Les Adelphes : «[des choses] que je porte à Chypre ${ }^{71}$. " Dans Phormion: «celle pour qui tu es venu de Lemnos, Chrémès ${ }^{72}$. " Dans la même comédie : "Je dirai aux vieux que je vais à Sunium au marché73.» Il a fréquenté les palestres, il a été musicien. Dans L'Eunuque: «Fais-en l'épreuve dans la palestre, dans la musique. Tout ce qu'un jeune homme doit savoir, je te montrerai qu'il le sait ${ }^{74}$. »

Imo praeter logicen et ethicen, alia quaedam in hoc poeta diligenter perpendenda sunt, quae essent ad maiorem industriam incumbendi literis incitamenta. Hoc tibi habeo polliceri, cyclopediae studiosum non uulgarem sub poeta hic exprimi. Pauca quaedam adducam, quibus illius insignis et admiranda eruditio colligeretur. In Andria: Quod plerique omnes faciunt adolescentuli, ut animum ad aliquod studium adiungant, aut equos alere, aut canes ad uenandum, aut ad philosophos, et cae. Nam postquam Terentius excessit ex ephebis, his adolescentulorum exercitiis floruisse, ex Mimis constat. Siquidem i $\pi \pi i k \grave{\eta}$ militiae, (cuius encomium apud Cicero in Orat. pro L. Murena extat) quod in Thrasone exercitus instructio satis ostendit, item quod P. Scipioni et Laelio hominibus nobilibus se dedit, eorumque studiis

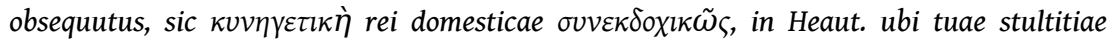

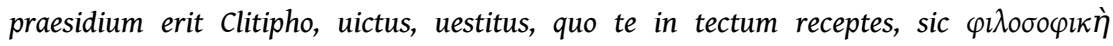
bonarum literarum studium, in Eun. fac periculum in literis, etc. designat. Fuit insignis physiognomon in Heaut. sparso ore, adunco naso ? non possum pater, rubor color est hominis malefici, sicut nasus aduncus signum est impudentis. Aristot. in Physi. Quibus nasus mox a fronte aduncus deducitur, impudentes, refertur ad ceruos. Fuit augurii peritus, in Phorm. Introiit in aedes ater alienus canis. Anguis per impluuium decidit de tegulis, gallina cecinit. Qui locus augurem requirit, ueteres enim in eam opinionem adducti, talia monstra esse omen nuptiarum parum felicium dicebant. Per introitum atri alieni canis, adulterii subsequuturi notam, per casum anguis de tegulis, alterum coniugatorum ueneno

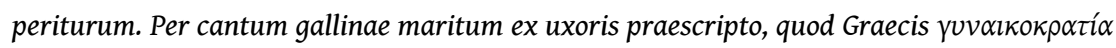
dicitur, uicturum, aut certe uxorem marito superstitem mansuram pronunciabant. Fuit magnus Physicus, in Adelph. Membra metu debilia, animus timore obstupuit. Pectore consistere nihil consilii quit. In eadem Comoedia, Erubuit, salua res est. Ruborem signum esse pudoris philosophi tradunt, in eadem, Laudarier te audit libenter, facio te apud illum deum uirtutes narro homini ilico lachrumae cadunt, quasi puero, gaudio, in Eunuch. Sine Baccho et Cerere friget Venus. perit enim libido sobrietate. In eadem. Tremo horreoque postquam aspexi hanc. Ratio est, ex sanguinis in cordis thalamos concursu, propter cupiditatem uehementiorem, qui cum rursus diffunditur, fit calor, qui ibidem ignis est, inualescens ex amicae conspectu, in Heaut. Mulier telam deserit continuo, et lachrymis opplet os totum sibi ut facile scires desiderio id fieri tuo. Insperatum gaudium saepe lachrymas excutere solet. Quis negaret ipsum Geographiam non ignorasse, in And. Fuit olim quidam senex mercator, nauem is fregit apud Andrum insulam. In Heaut. ubi mihi dixti, cupere te ex Aethiopia ancillulam. In Adelph. Quae porto Cyprum. In Phor. qua profectus caussa hinc es Lemnum Chreme. In eadem Comoedia Ego me ire senibus Sunium dicam ad mercatum. Fuit et palestrites et Musicus. In Eunuch. Fac periculum in palaestra, in musicis, quae scire aequum est adolescentem, solertem tibi dabo.

Et quoi! il n'a pas été étranger à ce qu'on appelle les sciences des facultés ${ }^{75}$ ! Lesbie, dans L'Andrienne, témoigne qu'il a possédé la connaissance de la médecine : «Jusqu'ici, 
Archilis, les signes habituels qui indiquent qu'elle se rétablit, je les vois tous chez elle $^{76}$. " C'est la méthode et l'art des médecins dogmatiques ${ }^{77}$. Dans la même comédie : «Qu'on lui donne à boire ce que j'ai ordonné, et la quantité prescrite " $^{78}$. Cela relève de la Diététique. Dans Les Adelphes, « La jeune fille est devenue enceinte des suites de ce viol : c'est maintenant le dixième mois $»^{79}$. C'est le mois d'un enfantement normal et à terme. Certains passages prouvent aussi qu'il se connaissait en droit. Dans L'Andrienne, "Avoir l'âme assez dévoyée pour prétendre, contre les lois et coutumes de ses concitoyens, contre la volonté d'un père, posséder cette créature dans le comble du déshonneur ${ }^{80}$ ! ». Ménédème, dans l'Heautontimoroumenos, réclame à Chrémès une femme pour son propre fils. Chrémès a dit que le gendre lui plaît et qu'enfin, s'il veut, il peut lui dire aussi «qu'elle est promise ${ }^{81}$. Dans Phormion, Antiphon aurait été écarté de sa fiancée si, contre tout espoir, une méprise n'était venue les secourir tous deux. Ainsi Lachès dans L'Hécyre : «J'ai plaidé et débattu avec toi [...]. J'ai dit qu'il était temps : sur mes instances tu as épousé ${ }^{82}$." Voilà qui touche de très près au droit. Le jurisconsulte Modestin ${ }^{83}$ dit au sujet de la cérémonie du mariage : "Les noces ne sont pas valides s'il n'y a pas consentement de tous, c'est-à-dire de ceux qui s'unissent ou de ceux dont ils dépendent ». L'évêque Eucharistus déclare de même dans les décrets canoniques sur les mariages clandestins : «Le mariage n'est pas légitime s'il n'est fait par ceux qui ont visiblement l'autorité sur la femme ; et si l'épouse n'est demandée à ceux qui en ont la garde, et si elle n'est fiancée par les parents et les proches ${ }^{84}$. » Et les écrits de Justinien traitent de l'enlèvement des filles : «Que celui qui voudrait se marier avec une femme, qu'elle soit libre ou affranchie, demande, conformément aux lois et à l'ancien usage, à ses parents ou aux personnes compétentes, que leur accord permette la légitimité du mariage ${ }^{85}$. » Au reste, il n'est pas douteux que Térence ait été un expert reconnu en droit. Dans Phormion: "Il y a une loi qui veut que les orphelines épousent leurs plus proches parents, et cette même loi oblige ces derniers à les prendre pour femmes ${ }^{86}$. " Dans la même comédie : « Les lois ne permettent pas à un esclave de plaider une cause, et il ne peut prêter serment ${ }^{87}$." Dans L'Andrienne, Criton, le cousin de Chrysis, déclare : "Par sa mort, c'est à moi que ses biens sont légalement revenus ${ }^{88}$. " Dans Les Adelphes, "Qu'est-ce qui te permet de prendre une femme qui est à moi, pour qui j'ai donné de l'argent?» Au même endroit, Sannion dit, alors qu'Eschine voudrait l'accabler de verges : «Et l'on dit que la liberté est la même pour tous ! " Et peu après : «Je crois qu'elle n'est pas à vendre parce qu'elle est libre ${ }^{89}$." Dans L'Eunuque, "J'ai demain un procès [...]; prends bien soin de dire à ton père qu'il se souvienne de me servir de témoin demain matin ${ }^{90}$. " Mais, et c'est la chose la plus louée de toutes, il est clair que Térence, à la manière païenne, a cultivé la Théologie elle-même. Dans Phormion: «Et moi, (c'est Déméa qui parle) je retourne chez moi saluer mes dieux pénates ${ }^{91}$. » Avant toutes choses, il faut chercher le royaume de Dieu. Dans L'Andrienne : «Dieux ! je vous prie, donnez à celle-ci le pouvoir d'accoucher ${ }^{92}$. » C'est la marque d'une invocation divine. Dans Les Adelphes: "Quoi ? tu croyais que les dieux te tireraient d'affaire pendant ton sommeil?" C'est que Dieu assiste celui qui agit. Au même endroit : "Va à la maison prier les dieux qu'ils te permettent d'emmener ta femme. » Une bonne épouse vient de Dieu. Au même endroit: «Va, père, toi plutôt, prier les dieux. Car je sais à coup sûr qu'ils t'écouteront mieux : tu es tellement meilleur que moi ${ }^{93}$. " Demandez et vous recevrez. Dans Phormion, "Il rendait grâces aux dieux » ; dans la même comédie : "C'est à bon droit que j'offre et rends aux dieux de grandes actions de grâce ${ }^{94}$. » L'action de grâces sied aux Chrétiens. 
Quid quod neque a facultatibus quas uocant, alienus fuerit? Medicinae scientiam habuisse testatur Lesbia in And. his uerbis: Adhuc Archillis, quae assolent, quaeque oportet signa ad salutem esse, omnia huic esse uideo. Haec sunt $\lambda$ oүı $\kappa \tilde{\omega} v$ rationis et artis. Ibidem : Quod iussi ei dare bibere, et quantum imperaui date, Diae<te>tica haec sunt. In Adelph. Virgo ex compressu grauida facta est, mensis hic decimus. Qui mensis legitimi et iusti est partus. Affirmant et quidam loci fuisse Iurisperitum. In And. Adeon' impotenti esse animo, ut praeter ciuium morem, atque legem, praeter sui uoluntatem patris, tamen hanc habere studet cum summo probro. Menedemus in Heaut. filio suo Cliniae uxorem ab ipso Chremete deposcit, et Chremes dixit, generum sibi placere, et postremo inquit, etiam si uolet desponsam quoque dicito. In Phor. depellitur Antipho a sponsa sua, nisi utrique praeter spem succurrisset error. Sic Laches in Hecy. Egi atque oraui tecum. Tempus dixi esse, impulsu duxisti meo. Haec iuribus prorsus affinia sunt. Modestinus Iurecons. de ritu nuptiarum inquit : Nuptiae consistere non possunt, nisi consentiant omnes, id est, qui coeunt, quorum'ue in potestate sunt. Hoc idem testatur Eucharistus pontifex de Clandest. spons. inter decreta his uerbis : Legitimum non sit Matrimonium, nisi ab his, qui super foeminam, dominationem habere uidentur, et a quibus custoditur, uxor petatur, et a parentibus, et propinquioribus sponsetur. Et rescripta Iustiniani de raptu uirginum perhibent. Quicunque uxorem uoluerit ducere siue ingenuam, siue libertinam secundum leges, et antiquam consuetudinem parentes, uel alios quos decet, petat, ut eorum uoluntate fiat legitimum coniugium. Atqui dubium non est, quin fuerit legum peritus celebris, in Phor. Lex est, ut orbae, qui sint genere proximi, his nubant, et illos ducere, eadem haec lex iubet. In eadem Comoedia, Seruum hominem caussam orare leges non sinunt. Neque dictio testimonii est. In And. Crito sobrinus Chrysidis inquit: Eius morte ea ad me lege redierunt bona. In Adel. Qui tibi licet meam habere, pro qua ego argentum dedi. ibidem Sannio dicit, cum ipsum loris opperire uellet Aeschinus, hiccine libertatem aiunt esse aequam omnibus et paulo post. Neque uendundam censeo, quae libera est. In Eun. Cras est mihi iudicium, ut diligenter nuncies patri, aduocatus mane mi esse ut meminerit. Quod uero omnium laudatissimum est, Terentium more Aethnico ipsam Theologiam coluisse liquet. In Phor. At (Demea loquitur) ego deos poenates hinc salutatum domum reuertar. Ante omnia quaerendum est regnum Dei. In And. Dii date facultatem obsecro huic pariundi, inuocationis diuinae est nota. In Adel. Quid? credebas dormienti haec tibi confecturos Deos. Conanti Deus adesse solet. ibidem. Abi domum, ac Deos comprecare, ut uxorem accersas. Vxor bona a domino. Ibidem. Abi pater, tu potius Deos comprecare. Nam tibi eos, certo scio, quo uir melior multo es quam ego, obtemperaturos magis. Petite et accipietis. In Phor. Diis gratias agebat, in eadem Comoedia, Diis magnas merito gratias habeo atque ago. Gratiarum actio decet Christianos.

17 C'est pour ces qualités que je t'invite à t'attacher à notre auteur comique, à le garder en mains, à l'user à force de le feuilleter, à le choyer et le chérir. Je t'invite de toute mon âme à consacrer le plus possible à Térence, quand ton âge croissant augmentera ta sagesse, ton application et ta diligence. De la connaissance parfaite de ses ouvrages, tu recueilleras des fruits abondants et durables grâce à l'élégance qui naît du juste choix des termes, des vérités qu'il énonce et des sujets qu'il traite. Et tes mœurs, encore malléables, tu les formeras si bien à la modestie, à la politesse, aux devoirs de la vie civile, et assurément à la piété, qu'elles te vaudront des louanges et te ménageront des amis. Tu mettras tout ton zèle à ce que tes mœurs y trouvent leur modèle. La divinité t'a doué d'un naturel fort heureux ; les vers de Virgile que tu entendis de moi en furent la preuve car, non seulement tu les redis sur-le-champ mais tu les confias fidèlement à ta mémoire. Cet événement a fait espérer ton érudition et ta piété futures ; pourvu que ton père obtienne de toi ce fruit en échange de ses peines, il ne réclamera rien de plus et tu ne pourras lui faire plaisir plus grand. Considérer ton naturel remarquable me confirme entièrement dans l'idée que tu répondras à mes souhaits et que tu «tiendras de ton père ", c'est-à-dire que tu feras revivre le nom très saint de l'érudition et de la piété $^{95}$. Je ne veux pas te laisser ignorer, mon petit Josse, qu'alors que je fréquentais l'école, beaucoup de citoyens de Reszel me vantaient souvent la diligence bien connue 
de ton très cher père, attestant que rien dans sa jeunesse ne lui fut plus doux que l'étude des Muses, tout comme encore maintenant. Car lorsque le jeudi après le repas, selon la coutume de l'école de Reszel, le maître s'adonnait au loisir lettré qu'on appelait récréation, notre cher Willich, "à la droite volonté ", comme tout disposé à cueillir "les racines amères de l'éducation, et, en vérité, ses fruits très doux ${ }^{96}$ ", dédaignant toutes les séductions des jeux et des spectacles, se retirait vers un mont élevé près de la ville, splendide par ses arbres, qu'on appelle Miraculeux, où l'on entend le murmure très charmant que fait l'eau d'un ruisseau, pour approfondir sa connaissance des belles lettres, et y appliquait son esprit avec sérieux. L'application d'un père si considérable, qu'elle te pousse et t'exhorte à continuer tes études, comme tu as commencé, et à les rendre glorieuses, pour que le nom de Reszel se fasse, grâce à toi, de plus en plus illustre. Pour que ta tâche soit plus aisée, nous invoquerons Dieu sempiternel, par la volonté duquel nous vivons, nous agissons et nous existons, pour qu'il illumine nos cœurs de son Saint Esprit, pour qu'illuminés par sa divine volonté, ils l'acceptent ; c'est par elle que notre Dieu qui habite aux cieux et regarde d'en haut notre terre, nous juge dignes, nous tous sans exception, selon l'ineffable clémence et l'ineffable miséricorde qui sont les siennes, de trouver place dans son royaume céleste, par notre Seigneur Jésus-Christ, Amen. Du Museum ${ }^{97}$, à l'époque de la fête du divin Michel, en l'an du salut retrouvé $1550^{98}$.

Propter has uirtutes hunc Comicum amplexandum, in manibus gestandum, iisdem terendum, fouendum atque exosculandum tibi suadeo. Teque ex animo commonefacio, ut cum per aetatem plus sapueris, huic Terentio, ita ut cum maxime operam diligentem ponas. Ex quo perdiscendo, uberes et diuturnos fructus propter elegantiam sermonis proprii, sententiarum et rerum percipies. Atque mores tuos cereos, ita modestos, excultos, ciuiles et quidem pios formabis, ut laudem inuenias, et amicos pares. Id unice studebis, formae, ut mores sint consimiles. Ingenium bene felix diuinitus tibi datum est, et quale haberes, indicio fuerunt uersus Vergiliani, quos a me auditos, non solum statim exposuisti, sed etiam fideliter memoriae mandasti. Ea res dedit aestimandi spem futurae eruditionis et pietatis, modo hunc fructum pro labore a te ferat pater, nihil amplius postulabit, neque hoc gratius quicquam illi facere potes. Praeclarae tuae indolis conspectus me penitus confirmat, te meis optatis responsurum et patrissaturum, hoc est, eruditionis et pietatis, nomen sanctissimum te relaturum. Nolo te latere mi Iodocule, quod complures ciues Reselliani illustrem illam patris tui charissimi diligentiam cum scholam frequentarem, saepe mihi decantabant. Cui praeter Musarum studium, nihil in pueritia, sicut et nunc id animi habet, unquam dulce fuisse, attestantes. Si quidem cum de more in schola Reselliana, die Iouis post prandium, ocium a literis, quod remissionem uocabant, praeceptor dedisset. Noster Vuillichius recht uuilligk, quasi promptus et facilis ad studiorum radices amaras, fructus uero dulcissimos, spretis omnibus ludorum et spectaculorum illectamentis, in montem quendam excelsum arboribus splendidum, qui Miraculosus dicitur, prope urbem, ubi iucundissimus fluuii praeterfluentis susurrus auditur, literis perdiscendis, sese abdidit, et grauiter ad easdem animum suum adiunxit. Huius tanti patris sedulitas, te commoueat commoneatque, ut studia recolas, sicut incoepisti, et magnifacias, quo fiet ut Reselliani nomen magis atque magis per te inclarescat. Id ut commodius fiat, Deum sempiternum, cuius nutu uiuimus, mouemur et sumus, inuocabimus, quo is Spiritu sancto corda nostra illuminet, illuminata illius diuina uoluntate acquiescant, qua Deus noster, qui in altis habitat, et humilia respicit, nos ad unum omnes, regni sui coelestis conciues pro sua ineffabili clementia et misericordia, facere dignetur, per Dominum nostrum Iesum Christum, Amen. Ex Musaeo circiter ferias diui Michaelis. Anno a recuperata salute 1550 . 


\section{NOTES}

1. Disponible sur: https://www.deutsche-biographie.de. La ville de Reszel, actuellement en Pologne, se trouvait au XVI ${ }^{\mathrm{e}}$ siècle en Prusse orientale et portait le nom allemand de Rössel.

2. In omnes Terentii fabulas compendiosa commentaria [...] Auto. D. Iodoco Willichio Reselliano. Adiectum est exemplar Terentii caeteris multo castigatius, Frankfurt/Oder, Johann Eichorn, 1550.

3. Voir par exemple l'editio triplex (Lyon, Macé Bonhomme, 1555).

4. Nous remercions Martine Furno et Francis Goyet pour leur relecture.

5. S.P.D : salutem plurimam dicit.

6. Économie (oeconomia) : le mot «économie » se dit au sens figuré «de la disposition d'un dessein, de la distribution d'un discours d'une pièce d'éloquence " (Dictionnaire de l'Académie, 1694). C'est pour Littré « l'arrangement réciproque et concourant des parties d'un ensemble, soit matériel, soit intellectuel ». L'expression «rerum reginae » vient de Cicéron, De Oratore, II, XLIV, 187, qui cite lui-même ce vers de Pacuvius : "flexanima atque omnium regina rerum oratio " («la parole est la charmeresse des cœurs et la reine du monde », selon la traduction E. Courbaud, Paris, Les Belles Lettres, «C. U. F. », 1966). Comme Cicéron dans ce passage, Gregor Wagner joue sur deux des sens d'oratio : « la parole » (en général) et « le discours en forme » (par opposition au sermo, les propos de la conversation).

7. Imitation de Virgile, Bucoliques, III, v. 54 : «sensibus haec imis (res est non parua) reponas", «accorde-nous une attention profonde (l'affaire est d'importance)» (trad. E. de Saint-Denis, Paris, Les Belles Lettres, «C. U. F. », 1970). On a dans tout ce début une allusion savante aux trois fonctions de l'exorde. La citation virgilienne souligne la nécessité de l'attentio. Le secundissima voluntas (l'heureuse décision) fait écho à la bene/volentia. Enfin, « mieux comprendre " renvoie à la docilitas ou désir de s'instruire qui doit animer le lecteur.

8. Anoikoinomèta: litt. « les choses mal arrangées ». Le terme, employé par le pseudo-Longin à propos d'Archiloque, est traduit par Boileau : « Archiloque qui [...] manque d'ordre et d'économie " (Longin, Traité du Sublime, trad. de Boileau, introduction et notes de F. Goyet, Paris, LGF, 1995, 33, 5). L'adjectif eutaktos (bien rangé, en bon ordre), qui relève du lexique militaire, prépare la comparaison introduite plus bas par la citation de Quintilien.

9. In inueniendo et diiudicando: ce renvoi ressemble à première vue au distinguo à l'intérieur même de l'inventio (d'abord on trouve les arguments, inuenire, puis on ne retient que les plus pertinents, iudicare). Mais comme on parle ici du lecteur, et non de l'auteur, le second terme évoque le iudicium au sens de "jugement critique » vu un peu plus haut ("porter un jugement plus exact » sur les beautés et les défauts d'un discours). Les deux interprétations ne s'excluent pas, puisque le lecteur est appelé, à force de relectures, à savoir composer lui-même.

10. Quintilien, Institution oratoire, VII, Avant-propos, § 2-3 (éd. et trad. Jean Cousin, Paris, Les Belles Lettres, «C. U. F. », 1970).

11. Il s'agit sans doute d'une allusion à la défaite de l'armée romaine contre Tarente, en 280 av. J.C. On trouve la même référence à la «Tarentina clades " à propos de la disposition chez Jakob Omphalius (1500-1567), Nomologia, qua eloquendi ac disserendi ratio..., Paris, Simon de Colines, 1536, p. 85 (et Cologne, Eucharius Cervicornus, 1538, p. 205).

12. Voir Donat, commentaire au prologue de L'Andrienne: "Principium factum a commendatione personae.» (Aelii Donati in Andriam Terenti commentum, Hyperdonat - Collection d'éditions numériques de commentaires anciens avec traduction, commentaire et annotation critique, disponible sur http://hyperdonat.tge-adonis.fr).

13. D'après Évanthius, « De fabula », IV, 5 (disponible sur le site Hyperdonat).

14. G. Wagner reprend l'incipit de l'adage $n^{\circ} 136$ d'Érasme (Adages, I, II, 36, «Catastrophe fabulae »: «Cujuslibet exitum rei proverbiali figura catastrophen vocamus »). 
15. Horace, Art poétique, v. 189-190 : « Neue minor neu sit quinto productior actu / fabula [...] 》, trad. François Villeneuve, Paris, Les Belles Lettres, « C. U. F. », 1955.

16. Voir Donat, préface à L'Andrienne, II, 3 : « est igitur animadvertendum, ubi et quando scaena uacua sit ab omnibus personis, ita ut in ea chorus uel tibicen obaudiri possint. »

17. Voir Érasme, Adages, I, II, 35 («supremum fabulae actum addere»), dont Wagner reprend la définition (" extremum finem imponere ») et la citation d'Horace.

18. G. Wagner vient ici de résumer la pièce scène par scène.

19. C'est la définition de la catastrophè. Voir Donat, préface à l'Andrienne, I, 5 : « et tamen repente ex his turbis in tranquillum peruenitur. »

20. Acte II, sc. 2. : Davos, Charinus, Pamphilus.

21. Dans son De Inventione (I, VIII, 10), Cicéron distingue quatre états de cause : conjecture (an sit), définition (quid sit), nature (quale sit), transfert (non jure). L'état conjectural porte sur le fait (Cicéron, ibid., I, VIII, 11).

22. L'attentio et la docilitas sont des notions propres à l'exorde, c'est-à-dire à l'entrée en matière qui s'achève par l'énoncé de la propositio, la thèse défendue.

23. Cicéron, De Inventione, II, XII, 41 : « Ensuite il faut voir ce qui est en rapport avec l'acte, c'est-àdire ce qui est plus ou moins grand, également grand ou semblable. On en tire quelque conjecture si l'on considère avec soin comment se déroulent habituellement des choses plus ou moins importantes ou également importantes ou semblables. " («Deinde uidendum est quid adiunctum sit negotio, hoc est quid maius, quid minus, quid aeque magnum sit, quid simile; ex quibus coniectura quaedam ducitur, si quemadmodum res maiores, minores, aeque magnae, similes agi soleant diligenter considerabitur. »; trad. G. Achard, Paris, Les Belles Lettres, « C. U. F. », 1994).

24. Acte II, sc. 3 : Syrus, Clinias, Clitiphon (v. 274-307). On est donc encore dans l'état conjectural.

25. Voir Tite-Live, Histoires, I, 57, 9.

26. Primae artes : les arts du trivium (grammaire, rhétorique, dialectique).

27. Artificii nota: les exemples sont les signes visibles de la technique oratoire, qu'ils permettent de mieux comprendre (la formule rappelle celle du tout début, artificii eliciti notationem). Voir Rhétorique à Herennius, IV, 7 : «cum de orationibus aut poematis elegeris exempla, quae certis signis artificii notata sunt "; " en choisissant dans les discours ou les œuvres en vers des exemples marqués indiscutablement du sceau de l'art» (trad. G. Achard, Paris, Les Belles Lettres, «C. U. F. », 2003, p. 132).

28. Cette citation, et celle qui la suit, ne viennent pas de Térence mais du commentaire de Guy Jouenneaux sur ce passage de l'Heautontimoroumenos, qui distingue entre promittere et polliceri.

29. Cette métaphore n'est pas nécessairement de registre familier, en latin comme en français de l'âge classique.

30. Cicéron, Pro Sexto Roscio Amerino, XVI, 47 : «etenim haec conficta arbitror esse a poetis ut effictos nostros mores in alienis personis expressamque imaginem vitae cotidianae videremus" (nous traduisons). G. Wagner omet vitae cotidianae, ce qui change un peu le sens (qui était « la peinture de nos mœurs et l'image vive de notre vie quotidienne »).

31. Cette définition et son attribution à Cicéron viennent du De comoedia et tragoedia que l'âge classique attribue à Donat et que l'époque moderne a rendu à Évanthius (Evanthii de comoedia excerpta, $\mathrm{V}, 1$ disponible en ligne sur le site hyperdonat).

32. Litt. «fournit la matière de la vertu (uirtutis materia) ». Même si le personnage n'exerce pas telle ou telle vertu que l'on attendrait (le courage, la tempérance, etc.), la situation elle-même est instructive pour la réflexion morale du lecteur ou du spectateur. Cette réponse à l'accusation d'immoralité de certaines scènes s'appuie, en gage de sérieux, sur le vocabulaire technique de l'éthique aristotélicienne et thomiste. Aristote, Éthique à Nicomaque, 1137b19 : la loi reste correcte, quelles que soient les fautes contre elle, « car la faute n'est pas inhérente à la loi ni au législateur, mais à la nature des choses dont il traite, car telle est dès l'abord la matière des actions possibles " (hè tôn praktôn hulè, en latin materia agibilis; trad. des CEuvres complètes, dir. P. Pellegrin, Paris, 
Flammarion, 2014). Thomas d'Aquin, Summa theologiae, $\mathrm{II}^{\mathrm{a}} \mathrm{II}^{\mathrm{ae}}, \mathrm{q} .58$, art. 1, début de la réponse : «Puisque, en effet, toute vertu est un habitus qui est le principe d'un acte bon, la vertu se définit nécessairement par l'acte bon relatif à la matière propre à la vertu. » (« per actum bonum circa propriam materiam virtutis", trad. M.-D. Couzinet, dans Diego Quaglioni, À une déesse inconnue. La conception pré-moderne de la justice, Paris, Publications de la Sorbonne, 2003, p. 76).

33. Térence, Les Adelphes, v. 415-416; le texte des éditions modernes porte " in vitas omnium ».

34. L'expression est empruntée à Érasme, préface aux Comédies de Térence (1532).

35. Aristote, Rhétorique, III, 2, 1405a : la traduction est de Pierre Chiron (Paris, GF Flammarion, 2007, p. 434).

36. Les Adelphes, III, 2, v. 315-319 (trad. J. Marouzeau, Paris, Les Belles Lettres, « C. U. F. », 1949).

37. Littera canina : la lettre R, qui mord (voir Perse, Satires, 1, 109).

38. Litt. « les représenter par l'imitation ». Wagner rend par le latin imitatio le grec mimèsis dans la Poétique d'Aristote : les acteurs imitent sur scène des actions réelles.

39. Citation de L'Eunuque, V, 4, v. 940.

40. Quod optimum [...] uidebitur, sibi non eligeret, sequereturque : la chute de la phrase retourne de façon positive les vers très célèbres où Médée dit « voir le bien, l'approuver et suivre le parti du mal» («Video meliora proboque, deteriora sequor », Ovide, Métamorphoses, VII, 20-21). Les élèves, ici, voient le mal, le désapprouvent et le fuient. Eligere est un terme clé de l'éthique : c'est le choix ou electio entre le bien et le mal.

41. Pour ce terme, le Dictionnaire grec-français d'A. Bailly renvoie encore à Denys d'Halicarnasse, La Composition stylistique, 23, 12. Mais l'édition G. Aujac et M. Lebel de cet ouvrage préfère la leçon sunekheia, mot de sens proche (Denys d'Halicarnasse, Opuscules rhétoriques, t. III, Paris, Les Belles Lettres, « C. U. F. », 1981, p. 168).

42. C'est-à-dire, à la lignée de ceux qui flattent ou se laissent flatter. Thrason est le soldat fanfaron de L'Eunuque, Gnathon le parasite qui le flatte, deux personnages empruntés à la pièce de Ménandre, Le flatteur (Colax).

43. Virgile, Géorgiques, II, v. 272 (nous traduisons, ici et ensuite).

44. Horace, Épîtres, I, 2, v. 69-70.

45. Platon, Lois, I, 643b. Ce n'est pas Platon, mais l'Étranger d'Athènes qui parle : « Assero equidem, eos, qui praestantes viri in aliquo evasuri sunt, ab ineunte statim pueritia oportere id ipsum tam ludendo, quam studendo » (traduction de Marsile Ficin, reprise par G. Wagner qui supprime le balancement " aussi bien en s'amusant qu'en s'y appliquant avec sérieux »).

46. G. Wagner résume ici le Pro Caelio de Cicéron, XXX-XXXI, 72-74.

47. Cicéron, Pro Archia, vII, 15.

48. Platon, Phèdre, 245a (avec entheos à 244b) : mais le relais est bien entendu Marsile Ficin et son commentaire sur le Banquet de Platon.

49. Ovide, Les Fastes, VI, v. 6-7 et L'Art d'aimer, III, v. 549-550.

50. Pro Archia, viII, 18. C'est la référence obligée de l'époque sur l'enthousiasme poétique, avec l' Ion de Platon.

51. Platon, Ion, 533e (sous-titré De furore poetico par Marsile Ficin). G. Wagner modifie à peine la traduction latine de Ficin, qui est exactement : « Omnes itaque carminum poetae insignes, non arte sed diuino afflatu mente capti omnia ista praeclara poemata canunt. "

52. Art poétique, v. 333-334.

53. Dans le discours qu'il prononça contre Vatinius, débauché proche de César, Cicéron l'accabla d'une série d'invectives qui passa en proverbe sous cette forme. Voir Érasme, Adages, II, II, 94 ( $\mathrm{n}^{\circ} 1194$, «Odium vatinianum »).

54. Les Adelphes, I, 2, respectivement v. 101-102 et v. 142-143.

55. L'Andrienne, I, 1, v. 55-57.

56. Ibid., v. 51.

57. Pro L. Licinio Murena, de IX, 20 à XI, 24. 
58. Heautontimoroumenos, V, 2, v. 967-968.

59. L'Eunuque, III, 2, v. 476-477.

60. Heautontimoroumenos, $\mathrm{V}, 5$.

61. G. Wagner cite la traduction que Josse Willich avait donnée du traité Physiognomonica attribué à Aristote (chap. X, « De naso » : Wittemberg, Schirlentz, 1538, non paginé).

62. Phormion, IV, 4, v. 706-708.

63. Les Adelphes, IV, 4, v. 613-614.

64. Ibid., IV, 5, v. 643.

65. Ibid., IV, 1, v. 535-537.

66. L'Eunuque, IV, 5, v. 732.

67. Ibid., I, 2, v. 84.

68. Héautontimoroumenos, II, 3, v. 305-307.

69. L'Andrienne, I, 4, v. 221-222.

70. Il s'agit en réalité de L'Eunuque, I, 2, v. 165-166.

71. Les Adelphes, II, 2, v. 230.

72. Phormion, IV, 1, v. 567.

73. Ibid., V, 7, v. 837-838.

74. L'Eunuque, III, 2, v. 478-479 («Fac in palaestra, in musicis: quae liberum / Scire aequomst adulescentem, sollertem dabo »).

75. C'est-à-dire la médecine, le droit et la théologie.

76. L'Andrienne, III, 2, v. 481-482.

77. Le terme de Logikoi désigne, en médecine, l'école de Galien ( $c f$. A. Bailly, Dictionnaire grecfrançais, s.v., p. 1199).

78. Ibid., v. 484-485.

79. Les Adelphes, III, 4, v. 474-475.

80. L'Andrienne, V, 3, v. 879-881 (trad. J. Marouzeau, op. cit., 1947).

81. Heautontimoroumenos, IV, 8, v. 864-866.

82. L'Hécyre, IV, 4, v. 686-687.

83. Juriste romain (III ${ }^{\mathrm{e}}$ siècle ap. J.-C.), élève d'Ulpien. La citation qui suit est, dans le Digeste, la loi 2 du titre De ritu nuptiarum.

84. Can. Aliter 30 quaest. 5 : texte attribué à Évariste, évêque d'Afrique (et non Eucharistus), dans Decretales pseudo-isidorianae, éd. P. Hinschius, Leipzig, Tauchnitz, 1863, p. 87 (voir Hélène Bricout, Le mariage entre consentement et bénédiction : le sacrement et son ministre, Paris, Éditions du Cerf, 2015).

85. Justinien, Code, livre IX, titre 13 (« De raptu virginum, seu viduarum, necnon sanctimonialium »).

86. Phormion, I, 2, v. 125-126 (trad. J. Marouzeau, op. cit., 1984).

87. Ibid., II, 1, v. 292-293.

88. L'Andrienne, IV, 5, v. 799.

89. Les Adelphes, II, 1, respectivement v. 179, v. 183 et v. 193-194.

90. L'Eunuque, II, 3, v. 338-340.

91. Phormion, II, 1, v. 310-312.

92. L'Andrienne, I, 4, v. 232-233.

93. Les Adelphes, IV, 5, respectivement v. 693, v. 699 et v. 703-705.

94. Phormion, respectivement IV, 3, v. 596 et V, 8, v. 894.

95. Pour l'emploi et le sens de patrissare, voir Les Adelphes, IV, 2, v. 564.

96. Mot attribué à Aristote par Diogène Laërce (Vie et doctrines des philosophes illustres, V, 18).

97. Le terme de museum désigne, à la Renaissance comme dans l'Antiquité, un lieu consacré aux Muses et aux études, c'est-à-dire une bibliothèque ou une académie. La présence d'une majuscule laisse penser qu'il ne s'agit pas d'un lieu privé, mais plutôt d'une dépendance de l'école où enseignait Wagner. 
98. Donc fin septembre ou début octobre 1550 (dans la religion catholique, les trois archanges sont fêtés le 29 septembre), date qui correspond peut-être à la fin d'une première période de cours, comme c'est souvent le cas encore aujourd'hui dans les pays anglo-saxons.

\section{AUTEURS}

\section{GREGOR WAGNER DE RESZEL}

Gregorius Wagnerus Resellianus (1512-1559) 